\title{
Systematic Review of Medication Synchronization in Community Pharmacy Practice
}

By

\author{
Michael Patti \\ Chelsea Phillips Renfro \\ Rachael Posey \\ Gabrielle $\mathrm{Wu}$ \\ Kea Turner \\ Stefanie Ferreri
}

\begin{abstract}
Honors Thesis
UNC Eshelman School of Pharmacy

University of North Carolina at Chapel Hill
\end{abstract}

January 14, 2019

Approved: 


\begin{abstract}
Background: Medication non-adherence costs more than 100 billion dollars in avoidable hospitalizations yearly. As a result, community pharmacies have implemented medication synchronization programs to improve adherence. One function of most medication synchronization programs is the alignment of all of a patient's medications to refill on a single date. While aligning refills is a standard aspect of most programs, other features vary making it difficult to identify which program components lead to improved adherence.
\end{abstract}

Objective: To review available literature and identify core components of medication synchronization and associated implementation techniques in community pharmacy.

Methods: A systematic review was performed by searching electronic databases for studies, reviews, and other sources for grey literature discussing medication synchronization in community pharmacy settings. Studies were eligible for inclusion if they documented the operation of medication synchronization program in a community pharmacy. A framework analysis identified common themes present in the literature.

Results: Twenty-six studies met criteria for final inclusion in this review. The majority of studies were retrospective cohorts, commentaries, and implementation guides. A wide variety of core components were included as part of medication synchronization program descriptions in the available literature. The authors were able to identify several core components that were consistent throughout most of the published literature. These components were the identification and enrollment of patients, inclusion of a medication review and patient assessment, the alignment of refills, a formal process for preparation of medications, and the delivery of medications and other services.

Conclusions: This review identified several common themes of medication synchronization in the literature. The authors believe this will help standardize medication synchronization within community pharmacy and facilitate future research. Themes found in this review provide the foundation upon which a consensus definition of medication synchronization can be built.

Keywords: medication adherence, community pharmacy services, medication synchronization 


\section{Systematic Review of Medication Synchronization in Community Pharmacy Practice}

Michael Patti, PharmD Candidate is a student pharmacist at UNC Eshelman School of Pharmacy, University of North Carolina at Chapel Hill.

Chelsea Phillips Renfro, PharmD, is an Assistant Professor at the University of Tennessee Health Science Center College of Pharmacy, Memphis, TN.

Rachael Posey, MLS was the Pharmacy Librarian and Coordinator of Systematic Review Services for the Health Sciences Library at the University of North Carolina at Chapel Hill while this review was being conducted. She currently is employed as the Health \& Life Sciences Research Librarian and Associate Director at the William Rand Kenan Jr. Library of Veterinary Medicine at North Carolina State University. Gabrielle Wu, PharmD Candidate is a student pharmacist at UNC Eshelman School of Pharmacy, University of North Carolina at Chapel Hill.

Kea Turner, MPH, MA, PhD is a postdoctoral fellow at the University of California at San Diego School of Medicine.

Stefanie P. Ferreri, PharmD, BCACP, CDE, FAPhA is Clinical Professor, Executive Vice-Chair and CoDirector, PGY1 Independent Pharmacy Ownership Residency Program, Division of Practice Advancement and Clinical Education, UNC Eshelman School of Pharmacy, University of North Carolina at Chapel Hill.

\section{Funding Sources}

This research did not receive any specific grant from funding agencies in the public, commercial, or notfor-profit sectors. 


\section{Introduction}

Patient non-adherence to prescribed therapy is a major driver of healthcare expenditures in the United States (U.S.). In a survey of 1,020 patients performed by the National Community Pharmacy Association, more than half reported multiple incidences of non-adherence each year. ${ }^{1}$ This pattern of non-adherence may be related to the numerous medications that patients are expected to manage. ${ }^{2}$ The Centers for Disease Control and Prevention (CDC) found that nearly $40 \%$ of adults, 65 years or older, reported taking 5 or more prescription medications. ${ }^{3}$ This medication burden has been shown to have a direct impact on adherence, as patients have identified that high frequency of pharmacy visits poses both economic and social hardships. ${ }^{4}$ To increase the likelihood of patient medication adherence, community pharmacies have begun offering medication synchronization programs specifically targeted at reducing the number of pharmacy visits.

Medication synchronization is a service offered in more than 20,000 pharmacies in the U.S. to alleviate poor medication adherence. ${ }^{5}$ Medication synchronization functions by aligning all a patient's medications to refill on a single date each month to minimize trips to the pharmacy. Due to the rapid growth of service, pharmacy associations offer many different medication synchronization programs, including programs by the American Pharmacists Association (APhA) and other organizations. ${ }^{6-8}$ While aligning all refills on one date is a standard aspect of these programs, other features of these programs, such as flexible payment plans, delivery options, and comprehensive medication reviews, are quite variable.

While aspects of the programs differ, medication synchronization has demonstrated a positive impact on adherence. Prior studies have indicated rates of adherence 2 to 6 times higher in patients enrolled in a medication synchronization program compared to patients managing their refills on their own. ${ }^{9-11}$ These adherence improvements have been shown, despite increased medication expenditure due to consistent refills, to reduce overall healthcare costs in populations enrolled in medication 
synchronization programs as well as improving operational efficiency and revenue for participating pharmacies. ${ }^{12-14}$

Because the components of medication synchronization programs are not standardized, it is difficult to identify which correlate with improved adherence. Few studies have attempted to characterize the differences between these programs, with most focusing on one pharmacy chain or users of a single medication synchronization program. ${ }^{10,11,15,16}$ A previous study by Krumme et al. attempted to identify the core components, or the features required to maintain the fidelity of the innovation of effective programs; however, this review used the recommendations of an expert panel to decide which programs, but not which components, were considered "exemplary." ${ }^{16}$ A common definition of the components and identification of the core components of medication synchronization is currently lacking in the literature. Without these items, it is difficult to determine the correlation between medication synchronization program features and improved adherence.

In addition to a need for defining the core components of medication synchronization, a description of the implementation of the program in pharmacies is also needed. While thousands of pharmacies have begun offering medication synchronization to patients, little information exists on the implementation of the service. Implementation science is the study of the environment and conditions required for successful implementation of an innovation or service. ${ }^{17,18} \mathrm{Few}$ studies have used implementation science to examine how medication synchronization is implemented. These studies focus only on a specific program, not the overarching components of medication synchronization programs as a whole. ${ }^{19}$

\section{Objective}

The objective of this study is to identify the core components of medication synchronization and their associated implementation techniques in community pharmacies. Identifying the core components of medication synchronization will allow researchers to examine which components of medication synchronization are associated with changes in patient outcomes. That way, pharmacies can 
focus implementation efforts on the components that drive performance and can eliminate ineffective components, saving time and resources.

\section{Methods}

This study was conducted according to PRISMA guidelines. ${ }^{20}$ Further details can be found in the protocol for this systematic review, which has been registered with the PROSPERO register of systematic reviews registration \#:CRD42016051371. ${ }^{21}$

\section{Search Strategy}

We searched for studies and reviews in MEDLINE ${ }^{\circledR}$ (via PubMed), Embase, and International Pharmaceutical Abstracts (IPA) from date of database inception through January 31, 2018 using general terms for medication, prescription, or refill combined with terms for synchronization or alignment or terms for appointment-based programs. We used medical subject headings (MeSH) or Embase subject headings (Emtree) where available and keywords when applicable. A complete list of MeSH terms and subject headings can be found listed in Table 1. We included additional grey literature from Google Scholar, pharmacy associations and corporate entities.

\section{Study Selection}

Criteria for study inclusion were English language documentation of the operation of medication synchronization program in a community pharmacy setting. The reviewers chose to include only English language literature due to the review's focus on the United States healthcare system and healthcare expenditures. Medication synchronization operations include implementation techniques, methods of patient enrollment, and clinical services offered as part of the program, such as comprehensive medication management, disease state management, patient education, point of care testing or vaccine recommendations. For the purposes of this study, a community pharmacy setting includes independent pharmacies, traditional chains, supermarket chains, mass-merchant chains, and outpatient pharmacies. The medication synchronization articles included a heterogeneous mixture of peer-reviewed and nonpeer-reviewed literature. The studies also included a mix of qualitative and quantitative studies that 
varied in study design. The authors decided to use an inclusive approach to selecting studies for the systematic review (e.g., including qualitative, multiple types of study designs) so that relevant articles were not excluded. This allowed the authors to obtain a comprehensive understanding of how medication synchronization has been implemented. We excluded articles that did not detail the operation of a medication synchronization program, those in a non-community pharmacy setting, abstracts, conference papers, and patents.

\section{Reporting of Findings and Framework Analysis}

It was initially planned to conduct a meta-analysis; however, due to the heterogeneity of studies found, this type of analysis was not able to be conducted. Therefore, extracted data have been summarized and reported qualitatively, and a framework analysis was conducted. A framework analysis was used because the study started with an a priori framework to guide the literature search. ${ }^{22}$ This method involves 1) familiarization - getting to know the literature for a given topic; 2) identifying a thematic framework that guides text selection from the studies; 3 ) indexing and charting - abstracting data from studies and organizing them within a matrix; and 4) interpretation - analyzing the data from each of the matrix cells and summarizing the data using descriptive statistics.

\section{Data Extraction}

Two authors independently extracted the following data using an electronic data collection form: Citation, PubMed ID (if applicable), year of publication, article objective(s), study population, study design, primary outcome, secondary outcome, number of community pharmacy sites, type of community pharmacy, location (country and state if applicable), medication synchronization program used, pharmacy team involvement and medication synchronization program features.

Data were sorted based upon the specific program features using the definitions set by Krumme et al. as a framework. These program features included, but were not limited to: technology to track patients and identify candidacy for synchronization, pharmacist consultation to 
reinforce adherence and link to other services, care integration, flexible solutions for patients, and techniques to ensure pharmacist/staff buy-in. ${ }^{16}$

\section{Data Analysis for Core Component Identification}

Data were analyzed by creating a matrix (i.e. Excel workbook) and abstracted text selections based on the framework. ${ }^{23,24}$ The authors reviewed the free-text descriptions of the medication synchronization programs and used similarities to group them into categories, using Krumme et al. as a framework, that would eventually inform the identification of core components of medication synchronization. When the research team encountered text selections that did not fit into the framework categories, the categories were modified to ensure that new data was not missed. Two authors reviewed the identified medication synchronization text selections and were able to reach consensus that these text selections best represented the available categories.

\section{Data Analysis for Implementation Strategies}

In addition to program features, data related to medication synchronization implementation were also synthesized and categorized using implementation strategies defined by Waltz et al and Powell et al. ${ }^{25-27}$ Implementation strategy was defined as "a systematic intervention process to adopt and integrate evidence-based health innovations (e.g., QI) into usual care" (p.124). ${ }^{27}$ These 9 strategies are as follows 1) Engage consumers; 2) Use evaluative and iterative strategies; 3) Change infrastructure; 4) Adapt and tailor to the context; 5) Develop stakeholder interrelationships; 6) Use financial strategies; 7) Support clinicians; 8) Provide interactive assistance; and 9) Train and educate stakeholders.

\section{Results}

Our search identified 1731 articles via database searching, and an additional 6 articles were found via the review of grey literature. Following removal of duplicates, 1587 articles were included for screening (Figure 1). Title and abstract screening identified 204 articles for full text 
review. A total of 178 articles were then excluded for: failing to describe a medication synchronization program $(n=75)$, available as abstracts/conference papers only $(n=52)$, patents ( $n=36)$, not being in the community pharmacy setting $(n=13)$, and the full-text not being available in English ( $n=2)$.

The 26 articles (Table 2) from the United States that met criteria for final inclusion included 7 retrospective cohort studies, 5 commentary articles, 3 implementation guides, 2 randomized control trials, 2 quasi-experimental, 2 cross-sectional studies, 1 prospective cohort study, 1 observational cohort study, 1 mixed-methods study, 1 review, and 1 association white paper. $8,10,11,15,16,28-48$

Twelve studies assessed the potential improvement in medication adherence associated with medication synchronization enrollment, with adherence most frequently defined as proportion of days covered $>0.8 .^{10,11,15,28,29,31-34,43,45,47,48}$ Only 2 studies, Didonato et al and Krumme et al (2018), assessed clinical outcomes associated with medication synchronization, which were systolic and diastolic blood pressures as an outcome of adherence to anti-hypertensive medication and incidence of major adverse cardiovascular events respectively. ${ }^{43} 33$

Of the included studies, the most common pharmacy practice environments for medication synchronization programs were independent pharmacies $(n=11)$, traditional chains $(n=4)$, supermarket chains $(n=4)$, non-specified chains $(n=4)$, and mass merchant chains $(n=1) .8,10,15,16,28,30$ $34,38,39,41-45,47,48$ Seven articles did not specify their practice setting beyond a general mention of community pharmacy or the identification of their target audience as community pharmacies. ${ }^{11,29,35-}$ 37,40,46 The most commonly identified medication synchronization program type was the appointment-based model $(n=12) \cdot{ }^{10,16,32-34,36-38,40,43,44,49}$ The observed program features as previously defined by Krumme et al were pharmacist consultation to reinforce adherence and link to other services $(n=21)$, flexible solutions for patients $(n=17)$, technology to track patients and 
identify opportunities $(n=16)$, care integration $(n=9)$, techniques for pharmacist buy-in $(n=4)$, and other $(n=2) .{ }^{8,10,11,15,16,28-48}$ The 2 other feature responses were technician training and providing patient enrollment cards. ${ }^{35,44}$

The results of the framework analysis revealed 5 common medication synchronization themes, representing potential core components, (Table 3) that appeared multiple times within the reviewed literature. These themes were: 1$)$ the identification and enrollment of patients $(n=14), 2)$ medication review and patient assessment $(n=6), 3)$ alignment of refills $(n=25), 4)$ preparation of medications ( $n=23)$, and 5) delivery of medications and other services $(n=22)$. The 3 most common themes, alignment of refills, preparation of medications, and delivery of medications and other services, focused on managing the patient from the point of refill alignment onwards. The 2 least common themes were enrolling appropriate patients and optimizing medication regimens prior to the initial refill alignment. Only 2 articles described a medication synchronization program that contained all five themes. ${ }^{11,30}$

Medication synchronization implementation data were extracted and grouped into nine categories utilizing the implementation framework published by Waltz et al (Table 4). ${ }^{26}$ All studies contained at least one identifiable implementation strategy. Overall, the most commonly occurring category of implementation technique was engaging consumers with all 26 studies offering techniques for engaging pharmacy customers. The remaining implementation strategies were observed with much lower frequencies in the reviewed literature. These were the use of evaluative and interactive strategies $(n=10)$, adapt and tailor to context $(n=12)$, develop stakeholder interrelationships $(n=11)$, train and educate stakeholders $(n=10)$, change infrastructure $(n=12)$, support clinicians ( $n=13)$, utilize financial strategies $(n=3)$, and lastly providing interactive assistance $(n=2)$, such as onsite technical support, was only observed twice. 


\section{Discussion}

Medication synchronization has been characterized as an adherence intervention involving multiple processes; central amongst these processes is the alignment of medications to refill. This definition is supported by 26 reviewed articles in the systematic review. However, due to the heterogeneity of study designs and included program descriptions a consensus definition of medication synchronization was not clear after the systematic literature review. Additionally, the lack in outcomes-based research seen in the available literature, adds support to the claim that medication synchronization is poorly defined. ${ }^{33,43}$

To effectively study outcomes associated with an intervention, that intervention must be clearly defined, and the current fractured nature of medication synchronization has limited the ability of researchers to study its clinical effects with only two identified studies looking directly at clinical outcomes as opposed to surrogate outcomes related to adherence. ${ }^{33,43}$ These studies selected a specific medication synchronization intervention which may not be generalizable to all medication synchronization programs. ${ }^{33,43}$

Based on the observed components, many programs treat medication synchronization as a process that starts with the alignment of refills, with most studies focusing on alignment, medication preparation, and medication delivery. ${ }^{15,16,35-37,39,40,42-44,46,48}$ Of the programs describing pre-alignment processes, the identification and enrollment of appropriate medication synchronization patients was the most common. This aspect of medication synchronization is one that is often overlooked. Medication synchronization may not be appropriate for all patients (e.g., patients taking as needed medications or whom are already highly adherent). ${ }^{15,37}$ Several programs had clearly defined enrollment criteria, often a particular number of chronic medications, to target those patients who might both best benefit from medication synchronization and be the best use of that pharmacy's resources. ${ }^{7,8,10,11,28-31,34,38}$ 
While it is clear that many programs seek to enroll the appropriate patients, what is less clear is a process for optimizing medication regimens prior to aligning refills. A basic medication review is shared by nearly all programs, but a comprehensive medication review for medication optimization prior to the initial medication alignment was rarely identified. ${ }^{11,28,30,41,45,47}$ This current practice is inefficient because the pharmacies dedicate a significant amount of time considering patient specific factors, such as patient finances or need for home delivery, when selecting a synchronization date and if a medication change is required post-synchronization the whole process must be repeated. If a patient's medications are not optimized (for example, an ACE inhibitor that is not at goal dose), then it would best serve the pharmacy to attempt to rectify this deficiency before synchronizing and filling. Additionally, pharmacists would be remiss not to use this opportunity for a comprehensive clinical review of medications to demonstrate their potential to improve patient outcomes through medication synchronization. However, there is a paucity of information in the literature on the programs' consideration of the clinical appropriateness of the medications to be synchronized.

The literature is consistent when discussing the processes of filling and delivering the patient's medications once the synchronization process is complete. Nearly all studies describe a process of contacting the patient approximately seven days prior to their synchronization date to confirm the medications to be refilled and address recent doctors' visits or hospitalizations. $8,10,11,15,16,28-32,34-36,38,40,42-48$ Once the medications have been filled the process of delivering medications is described in many studies as featuring an opportunity to provide other patient services, such as medication therapy management or immunizations. ${ }^{8,10,11,15,16,29-34,36,38,39,41-}$ $44,46,47$

While the core components of medication synchronization are a focus of this review, they are of limited utility without associated techniques for successfully implementing and operating a 
medication synchronization program. This review identified several interesting trends in how community pharmacies implement and operate their medication synchronization programs. As seen in Table 4, the most common implementation strategies focus on educating and recruiting patients into the medication synchronization programs $(n=26)$, but similar processes targeted at other stakeholders ( $n=11$ ), such as pharmacy staff and local healthcare providers, occur with much less frequency. ${ }^{8,10,11,15,16,28-48}$ This trend was also supported by the rare occurrence of techniques for pharmacist buy-in, as defined by Krumme et al, since only 4 were observed in the reviewed studies. ${ }^{16,36,37,46}$

A lack of stakeholder education and buy-in could pose a significant challenge to the success of a medication synchronization program, as stakeholders, including pharmacists, technicians, and cashiers, may be unable to handle the additional workflow created by aggressive patient recruitment. Lack of stakeholder buy-in also speaks to a missed opportunity for these pharmacies to communicate with local providers, and often forgotten group of stakeholders, to educate them regarding the potential advantages of medication synchronization programs. As seen in two studies, this has the potential to lead to a formalized referral process for non-adherent patients adding a new source of patients and revenue to the pharmacy. ${ }^{28,45}$

Given the challenging practice environment that community pharmacists are faced with, where the goal is to provide the best patient care while minimizing overhead cost, efficiently involving all staff members in medication synchronization operation is key. However, while the majority $(n=23)$ of studies describe pharmacist involvement, less than half $(n=12)$ make mention of how technicians are involved, and even fewer $(n=10)$ mention other staff such as cashiers. ${ }^{8,10,11,15,16,28-34,36-47}$ Whether this is due to the primary burden of medication synchronization falling on pharmacists or if the literature is not adequately capturing other staff participation needs additional research. 
Lastly, implementation of medication synchronization does not end once the first patient is synchronized, as there is always room to improve and optimize as more patients are recruited. While evaluative and interactive strategies were one of the more common implementation strategies seen in the literature $(n=10)$, the sub-strategies associated with continuous improvement such as quality monitoring $(n=4)$, auditing and providing feedback $(n=2)$, purposefully re-examining the implementation $(n=1)$, and obtaining and using patient/consumer feedback $(n=1)$ were all observed with relatively low frequency. This could indicate that community pharmacies may be allowing medication synchronization to stagnate instead of optimizing the intervention to maximize its efficiency and impact.

Taken as a whole, the components and implementation strategies observed in the literature create a preliminary picture of the core components required for a medication synchronization program. A medication synchronization program featuring the components observed in this review should contain a standardized process to; 1)target and enroll patients, 2)review the patient and their medications, 3)select the medications to be synchronized as well as their synchronization date based on patient specific factors, 4) contact the patient and prepare the medications for delivery, 5) delivery of the patient's medications. These components create a high touch program centered on overall patient care that can serve as an anchor for the multitude of clinical services that are gaining in popularity within community pharmacy practice.

The framework analysis conducted in this systematic review further supports core components of medication synchronization considered by Renfro et al. ${ }^{50}$ In that study the researchers vetted the core components found in this review with community pharmacy luminaries from across the United States. ${ }^{50}$ The luminary interviews found the core components to be essential functions for the practice of medication synchronization. 
A consistent definition of medication synchronization core components can be used to show both the clinical and financial benefits that medication synchronization may bring to community pharmacies. Utilizing these core components as a standard, future research can track if adherence to these components generates improvements in medication adherence in addition to clinical and financial outcomes. This can be used in community pharmacy practice to justify additional reimbursements based on the quality of their medication synchronization program.

\section{Limitations}

There are potential limitations associated with the methods of a systematic review. The first is the potential for selection bias as the authors chose to restrict reviewed literature to articles only published in the English language. Publication bias is another limitation inherent in systematic reviews as negative and non-significant study results are sometimes not submitted for publication. While this is not as significant in the case of this review as outcomes were not the focus, publication bias may have artificially restricted the quantity of literature available to the authors.

The reviewed literature was heterogenous in number and type of practice sites, as well as study designs and outcomes. The majority of the reviewed studies were qualitative or had a small sample size, thus limiting the generalizability of this review. This made it difficult for the authors to accurately weigh the significance of data. Additionally, the available literature in many instances did not thoroughly describe the medication synchronization intervention as part of their methods, which posed a challenge when attempting to identify core components. The heterogeneity of our dataset and the lack of consistent reporting across studies limited our ability to analyze the data in a systematic fashion resulting in a framework analysis. Further studies are needed that assess medication synchronization in a larger sample size.

\section{Conclusions}


The standardization of an intervention is a necessary prior to performing any outcomes-

based research. However, as is seen in this review of medication synchronization literature, the adherence intervention known as medication synchronization is not standardized in community pharmacy practice. Medication synchronization programs have the potential to become a standardized intervention linking multiple adherence and clinical services in community pharmacy practice. The standardization of medication synchronization programs across community pharmacy practice will help to ensure the quality of the medication synchronization programs offered to patients, thereby improving the overall quality of community pharmacy practice.

This review provides the foundation upon which a consensus definition of medication synchronization can be built. This is a key first step to performing outcomes-based research to prove the potential value medication synchronization can bring both to cost and clinical outcomes.

\section{References}

1. National Community Pharmacist Association. Medication adherence in America: a national report card. 2013; http://www.ncpanet.org/pdf/reportcard/AdherenceReportCardPresentationFINAL.pdf. Accessed November 5, 2018.

2. Odegard PS, Capoccia K. Medication taking and diabetes: a systematic review of the literature. Diabetes Educ. 2007;33(6):1014-1029; discussion 1030-1011.

3. National Center for Health S. Health, United States. Health, United States, 2015: With Special Feature on Racial and Ethnic Health Disparities. Hyattsville, MD: National Center for Health Statistics (US); 2016.

4. Brown MT, Bussell JK. Medication Adherence: WHO Cares? Mayo Clinic Proceedings. 2011;86(4):304-314.

5. Bonner L. Med Sync Catching on Across Nation. 2015; https://www. pharmacist.com/med-synccatching-across-nation. Accessed November 5, 2018.

6. Align My Refills. 2016; http://www.aphafoundation.org/align-my-refills/about-medsync. Accessed November 5, 2018.

7. Pharmacy's appointment based model: a prescription synchronization program that improves adherence. 2013;

http://www.aphafoundation.org/sites/default/files/ckeditor/files/ABMWhitePaper-FINAL20130923(3).pdf\#sthash.kfiyOeA8.dpuf. Accessed November 5, 2018.

8. Medication Synchronization Playbook. Health Mart Pharmacy. 2015.

9. Nguyen E, Sobieraj DM. The impact of appointment-based medication synchronization on medication taking behaviour and health outcomes: A systematic review. J. Clin. Pharm. Ther. 2017;42(4):404-413. 
10. Holdford D, Saxena K. Impact of Appointment-Based Medication Synchronization on Existing Users of Chronic Medications. J Manag Care Spec Pharm. 2015;21(8):662-669.

11. Holdford DA, Inocencio TJ. Adherence and persistence associated with an appointment-based medication synchronization program. J. Am. Pharm. Assoc. (2003). 2013;53(6):576-583.

12. Roebuck MC, Liberman JN, Gemmill-Toyama M, Brennan TA. Medication adherence leads to lower health care use and costs despite increased drug spending. Health Aff (Millwood). 2011;30(1):91-99.

13. Patterson JA, Holdford DA, Saxena K. Cost-benefit of appointment-based medication synchronization in community pharmacies. Am. J. Manag. Care. 2016;22(9):587-593.

14. Smart Retailing Rx. It's time to start offering medication synchronization. 2014; https://join.healthmart.com/patient-care-counseling/time-start-offering-medicationsynchronization/. Accessed November 5, 2018.

15. Hinson JL, Garofoli GK, Elswick BM. The impact of medication synchronization on quality care criteria in an independent community pharmacy. J. Am. Pharm. Assoc. (2003). 2017;57(2):236240.

16. Krumme AA, Isaman DL, Stolpe SF, Dougherty S, Choudhry NK. Prevalence, effectiveness, and characteristics of pharmacy-based medication synchronization programs. Am. J. Manag. Care. 2016;22(3):179-186.

17. Metz A. Practice Profiles: A Process for Capturing Evidence and Operationalizing Innovations. http://nirn.fpg.unc.edu/sites/nirn.fpg.unc.edu/files/resources/NIRN-Metz-WhitePaperPracticeProfiles.pdf. Accessed November 5, 2018.

18. Bauer MS, Damschroder L, Hagedorn H, Smith J, Kilbourne AM. An introduction to implementation science for the non-specialist. BMC Psychol. 2015;3:32.

19. Patterson J, Holdford D. Understanding the dissemination of appointment-based synchronization models using the CFIR framework. Res. Social Adm. Pharm. 2017;13(5):914-921.

20. Moher D, Liberati A, Tetzlaff J, Altman DG. Preferred reporting items for systematic reviews and meta-analyses: the PRISMA statement. PLoS Med. 2009;6(7):e1000097.

21. Renfro C, Ferreri S, Patti M, Wu G, Posey R. Identifying the core components of medication synchronization in community pharmacy. 2016;

http://www.crd.york.ac.uk/PROSPERO/display record.php?ID=CRD42016051371. Accessed November 5, 2018.

22. Dixon-Woods M, Cavers D, Agarwal S, et al. Conducting a critical interpretive synthesis of the literature on access to healthcare by vulnerable groups. BMC Med. Res. Methodol. 2006;6(1):35.

23. Ritchie J L, McNaughton Nicholls C, Ormston R. Qualitative research practice: A guide for social science students and researchers. Thousand Oaks, Ca: SAGE Publications Inc.; 2013.

24. Gale NK, Heath G, Cameron E, Rashid S, Redwood S. Using the framework method for the analysis of qualitative data in multi-disciplinary health research. BMC Med. Res. Methodol. 2013;13(1):117.

25. Waltz TJ, Powell BJ, Matthieu MM, et al. Use of concept mapping to characterize relationships among implementation strategies and assess their feasibility and importance: results from the Expert Recommendations for Implementing Change (ERIC) study. Implement Sci. 2015;10:109.

26. Powell BJ, Waltz TJ, Chinman MJ, et al. A refined compilation of implementation strategies: results from the Expert Recommendations for Implementing Change (ERIC) project. Implementation Science. 2015;10(1):21.

27. Powell BJ, McMillen JC, Proctor EK, et al. A compilation of strategies for implementing clinical innovations in health and mental health. Med. Care Res. Rev. 2012;69(2):123-157.

28. Barnes B. Appointment Based Medication Synchronization: A Comparison of Three Model Designs in a Large Chain Community Pharmacy Setting, University of Cincinnati; 2016. 
29. Blackburn DF, Tran D, Quiring C. Evaluation of a refill synchronization program in two community pharmacies. J. Am. Pharm. Assoc. (2003). 2016;56(6):656-659.

30. Faulks J. Driving patient adherence and outcomes through appointment-based refill programs. Vol 20172017.

31. Girdish C, Shrank W, Freytag $S$, et al. The impact of a retail prescription synchronization program on medication adherence. J. Am. Pharm. Assoc. (2003). 2017;57(5):579-584.e571.

32. Holdford D. Simplify My Meds Appointment-Based Medication Synchronization Pilot Study Report. Prepared for the National Community Pharmacists Association.

33. Krumme AA, Glynn RJ, Schneeweiss S, et al. Medication Synchronization Programs Improve Adherence To Cardiovascular Medications And Health Care Use. Health Aff. (Millwood). 2018;37(1):125-133.

34. Painter JT, Moore G. Addressing Medication Non-Adherence through Implementation of an Appointment-Based Medication Synchronization Network. Alexandria, VA: National Community Pharmacists Association.

35. Patient Centric Model: Operations Manual. National Alliance of State Pharmacy Associations.

36. Pharmacy's Appointment Based Model: A Prescription Synchronization Program that Improves Adherence. APhA Foundation White Paper. 2013.

37. Pharmacy's Appointment Based Model: Implementation Guide for Pharmacy Practice. APhA Foundation White Paper. 2013

38. Yap D. Improving adherence in appointment-based model. Pharmacy Today. 2013;19(11):42-43.

39. Larkin H. Patient care at med sync improves outcomes, revenue. Drug Topics. 2016;160(8).

40. Baugh J, Shilan J. Key Findings and Results of the Appointment Based Model. Vol 15:32.

41. Blank C. Synchronized meds boost patient adherence, pharmacy efficiency. Drug Topics. 2016;160(7).

42. Butler KT, Ruisinger JF, Bates J, Prohaska ES, Melton BL. Participant satisfaction with a community-based medication synchronization program. J. Am. Pharm. Assoc. (2003). 2015;55(5):534-539.

43. DiDonato KL, Vetter KR, Liu Y, May JR. Examining the effect of a medication synchronization or an education program on health outcomes of hypertensive patients in a community pharmacy setting. INNOVATIONS in. 2014.

44. Kadia NK, Schroeder MN. Community Pharmacy-Based Adherence Programs and the Role of Pharmacy Technicians: A Review. J. Pharm. Technol. 2015;31:51.

45. Omerza KE. The Economic Impact of a Pharmacy-Based Hybrid Medication Adherence Model in Patients with Metabolic Syndrome. 2015.

46. Pinto SL, Bechtol RA, Omerza K, Conner T. Determining patient satisfaction, perception of value, and monetary worth associated with adherence packaging and pharmacy services. Value Health. 2014;17(3):A139.

47. Andrews SB, Marcy TR, Osborn B, Planas LG. The impact of an appointment-based medication synchronization programme on chronic medication adherence in an adult community pharmacy population. J. Clin. Pharm. Ther. 2017;42(4):461-466.

48. Talsma J. Med synchronization through community pharmacies brings greater adherence. Drug Topics. 2014(MAR).

49. Medication Syncrhonization Playbook. Health Mart Pharmacy. 2015.

50. Renfro CP, Patti M, Ballou JM, Ferreri SP. Development of a medication synchronization common language for community pharmacies. J. Am. Pharm. Assoc. (2003). 2018;58(5):515521.e1 
Figure 1: Study Selection Process

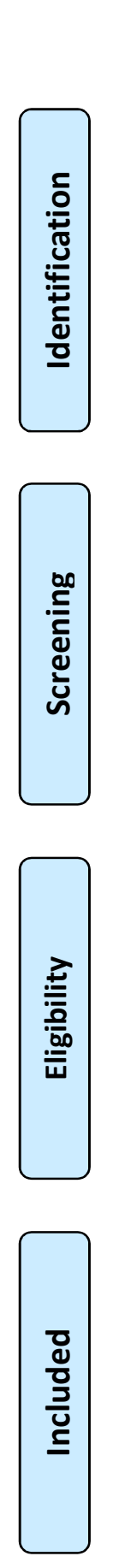

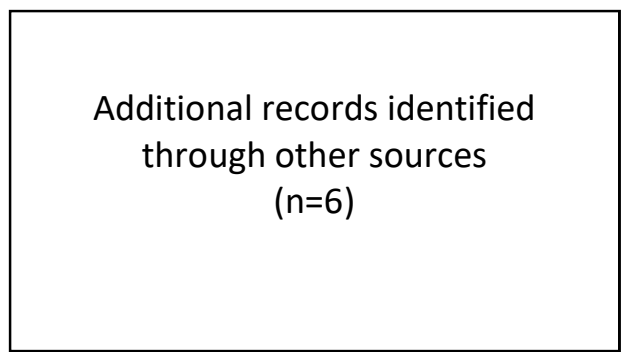

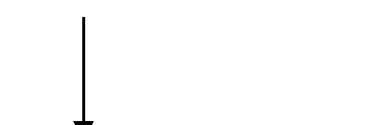

Records after duplicates removed

$$
\text { ( } n=1587)
$$

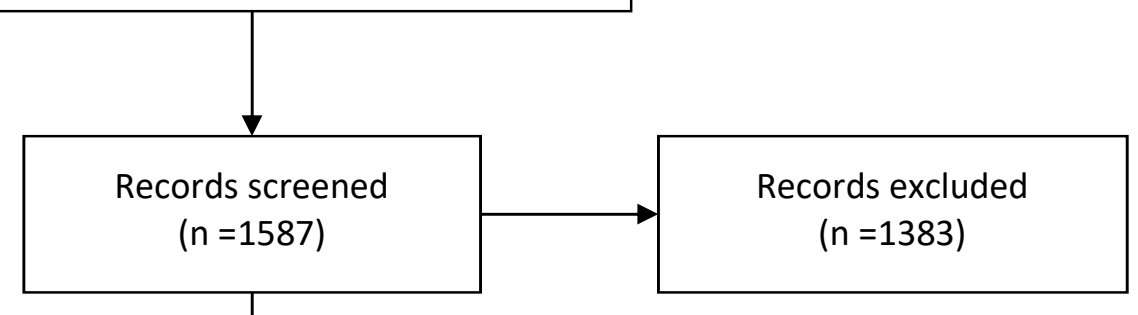

Full-text articles excluded, with reasons

No description of medication synchronization program $(n=75)$ Abstract: $(n=52)$ Patent: $(n=36)$ Wrong Setting: $(n=13)$ Not available in English $(n=2)$

Studies included in qualitative synthesis

$$
(n=26)
$$


Table 1: Search Terms and Associated Databases

\begin{tabular}{|c|c|}
\hline Pubmed & Queried Terms \\
\hline \#1 & $\begin{array}{l}\text { (medication[tw] OR prescription[tw] OR medications[tw] OR } \\
\text { prescriptions[tw] OR refill[tw] OR refills[tw]) }\end{array}$ \\
\hline$\# 2$ & $\begin{array}{l}\text { (synchronization[tw] OR synchronized[tw] OR alignment[tw] OR aligns[tw] } \\
\text { OR aligning[tw]) }\end{array}$ \\
\hline \#3 & (\#1 AND \#2) \\
\hline$\# 4$ & ("appointment based"[tw] OR (med[tw] AND sync[tw])) \\
\hline$\# 5$ & (\#3 OR \#4) \\
\hline \multicolumn{2}{|l|}{ IPA } \\
\hline S1 & $\begin{array}{l}\text { TI ( (medication OR prescription OR medications OR prescriptions OR refill } \\
\text { OR refills) ) OR AB ( (medication OR prescription OR medications OR } \\
\text { prescriptions OR refill OR refills) ) OR SU ( (medication OR prescription OR } \\
\text { medications OR prescriptions OR refill OR refills)) }\end{array}$ \\
\hline S2 & $\begin{array}{l}\text { TI ( (synchronization OR synchronized OR alignment OR aligns OR aligning) } \\
\text { ) OR AB ( (synchronization OR synchronized OR alignment OR aligns OR } \\
\text { aligning) ) OR SU ( (synchronization OR synchronized OR alignment OR } \\
\text { aligns OR aligning)) }\end{array}$ \\
\hline S3 & S1 AND S2 \\
\hline S4 & $\begin{array}{l}\text { TI ( "med sync" OR "appointment based" ) OR AB ( "med sync" OR } \\
\text { "appointment based" ) OR SU ( "med sync" OR "appointment based" ) }\end{array}$ \\
\hline S5 & S3 OR S4 \\
\hline \multicolumn{2}{|l|}{ Embase } \\
\hline$\# 1$ & $\begin{array}{l}\text { 'medication':de OR medication OR 'prescription'/exp OR medications OR } \\
\text { 'prescriptions':de OR prescription OR prescriptions OR refill OR refills }\end{array}$ \\
\hline$\# 2$ & synchronization OR synchronized OR alignment OR aligns OR aligning \\
\hline$\# 3$ & \#1 AND \#2 \\
\hline$\# 4$ & 'med sync' OR 'appointment based' \\
\hline$\# 5$ & \#3 OR \#4 \\
\hline$\# 6$ & \#3 OR \#4 AND [medline]/lim \\
\hline$\# 7$ & \#5 NOT \#6 \\
\hline \multicolumn{2}{|l|}{$\begin{array}{l}\text { Google } \\
\text { Scholar }\end{array}$} \\
\hline$\# 1$ & $\begin{array}{l}\text { "medication synchronization" OR "medication alignment" OR } \\
\text { "prescription synchronization" OR "prescription alignment" OR "refill } \\
\text { synchronization" OR "refill alignment" OR "med sync" OR "appointment } \\
\text { based model" } \\
\text { (Excluding patents) }\end{array}$ \\
\hline
\end{tabular}


Table 2: Characteristics of Studies Included in the Review

\begin{tabular}{|c|c|c|c|}
\hline Study (No. of Sites) & $\begin{array}{c}\text { Community } \\
\text { Pharmacy Setting }\end{array}$ & Study Design & $\begin{array}{c}\text { Medication } \\
\text { Synchronization Program } \\
\text { Used }\end{array}$ \\
\hline $\begin{array}{c}\text { Andrews et. al. } 2017^{46} \text { (18 } \\
\text { sites) }\end{array}$ & Independent & Quasi-experimental & Time My Meds \\
\hline Barnes B. $2016^{27}$ (31 sites) & Supermarket chain & $\begin{array}{l}\text { Prospective cohort } \\
\text { study }\end{array}$ & Not Specified \\
\hline $\begin{array}{l}\text { Baugh J, Shilan J. } 2012^{39} \\
\text { (N/A) }\end{array}$ & Not specified & Commentary/News & $\begin{array}{l}\text { NASPA Appointment Based Model } \\
\text { (ABM) }\end{array}$ \\
\hline $\begin{array}{c}\text { Blackburn et. al. } 2016^{28} \text { ( } 2 \\
\text { sites) }\end{array}$ & Not specified & $\begin{array}{l}\text { Retrospective cohort } \\
\text { study }\end{array}$ & Not specified \\
\hline Blank C. $2016^{40}$ (82 sites) & Independent & Commentary/News & StarWellness \\
\hline Butler et. al. $2015^{41}$ ( 1 site) & Supermarket chain & Cross-sectional study & Time My Meds (TMM) \\
\hline $\begin{array}{l}\text { DiDonato et. al. } 2014^{42} \text { ( } 15 \\
\text { sites) }\end{array}$ & Independent & $\begin{array}{c}\text { Randomized controlled } \\
\text { trial }\end{array}$ & ABM \\
\hline Faulks J. $2017^{29}$ (N/A) & Chain (not specified) & Commentary/News & Thrifty White's RxMedSync model \\
\hline Girdish et. al. $2017^{30}$ (N/A) & Traditional chain & $\begin{array}{l}\text { Retrospective cohort } \\
\text { study }\end{array}$ & CVS's ScriptSync \\
\hline $\begin{array}{l}\text { Hinson et. al. } 2017^{15} \text { ( } 1 \\
\text { site) }\end{array}$ & Independent & $\begin{array}{l}\text { Retrospective cohort } \\
\text { study }\end{array}$ & Not Specified \\
\hline
\end{tabular}




\begin{tabular}{|c|c|c|c|}
\hline $\begin{array}{l}\text { Holdford D. Prepared for } \\
\text { the National Community } \\
\text { Pharmacists Association. }{ }^{31} \\
\text { ( } 3 \text { sites) }\end{array}$ & Traditional chain & $\begin{array}{l}\text { Retrospective cohort } \\
\text { study }\end{array}$ & ABM \\
\hline $\begin{array}{l}\text { Holdford et. al. } 2013^{11} \\
\text { (N/A) }\end{array}$ & Not specified & $\begin{array}{l}\text { Retrospective cohort } \\
\text { study }\end{array}$ & Sync My Meds \\
\hline $\begin{array}{l}\text { Holdford et. al. } 2015^{10} \text { (71 } \\
\text { sites) }\end{array}$ & Chain (not specified) & Quasi-experimental & ABM \\
\hline Kadia et. al. $2016^{43}(\mathrm{~N} / \mathrm{A})$ & Traditional Chain & Review & $\begin{array}{c}\text { Script Your Future, Simplify My } \\
\text { Meds, ABM }\end{array}$ \\
\hline $\begin{array}{l}\text { Krumme et. al. } 2016^{16} \\
\text { (5534 Sites) }\end{array}$ & $\begin{array}{l}\text { Independent,Chain (not } \\
\text { specified),Traditional } \\
\text { chain,Supermarket } \\
\text { chain,Mass merchant chain }\end{array}$ & Mixed methods & ABM and Simplify My Meds \\
\hline $\begin{array}{l}\text { Krumme et al. } 2018^{32} \\
\text { (1200 sites) }\end{array}$ & $\begin{array}{c}\text { Chain (not } \\
\text { specified),Supermarket } \\
\text { chain }\end{array}$ & $\begin{array}{l}\text { Retrospective Cohort } \\
\text { Study }\end{array}$ & ABM \\
\hline Larkin H. $2016^{38}$ (N/A) & Independent & Commentary/News & Not Specified \\
\hline $\begin{array}{c}\text { Medication } \\
\text { Synchronization Playbook. } \\
\text { Health Mart Pharmacy. } \\
2015^{48}\end{array}$ & Independent & Implementation Guide & Heath Mart ABM \\
\hline Omerza K. $2015^{44}$ (N/A) & Independent & $\begin{array}{c}\text { Randomized controlled } \\
\text { trial }\end{array}$ & Not Specified \\
\hline $\begin{array}{l}\text { Painter et. al. } 2015^{33} \text { ( } 82 \\
\text { sites) }\end{array}$ & Independent & $\begin{array}{l}\text { Retrospective cohort } \\
\text { study }\end{array}$ & $\begin{array}{l}\text { Simplify My Meds and } \\
\text { StarWellness, ABM }\end{array}$ \\
\hline $\begin{array}{l}\text { Patient Centric Model: } \\
\text { Operations Manual. } \\
\text { National Alliance of State } \\
\text { Pharmacy Associations. }\end{array}$ & Not specified & Implementation Guide & Patient Centric Model \\
\hline
\end{tabular}




\begin{tabular}{|c|c|c|c|}
\hline $\begin{array}{l}\text { Pharmacy's Appointment } \\
\text { Based Model: A } \\
\text { Prescription } \\
\text { Synchronization Program } \\
\text { that Improves Adherence. } \\
\text { APhA Foundation White } \\
\text { Paper. } 2013^{35} \\
\end{array}$ & Not specified & White Paper & ABM \\
\hline $\begin{array}{l}\text { Pharmacy's Appointment } \\
\text { Based Model: } \\
\text { Implementation Guide for } \\
\text { Pharmacy Practice. APhA } \\
\text { Foundation White Paper. } \\
2013^{36} \\
\end{array}$ & Not specified & Implementation Guide & $A B M$ \\
\hline Pinto et. al. $2014^{45}$ (1 site) & Not specified & Cross-sectional study & Not Specified \\
\hline Talsma J. $2014^{47}$ (10 sites) & Independent & Observational Cohort & Not Specified \\
\hline Yap D. $2013^{37}$ (2 sites) & Independent & Commentary/News & ABM \\
\hline
\end{tabular}


Table 3: Medication Synchronization Framework

\begin{tabular}{|c|c|c|c|}
\hline $\begin{array}{l}\text { Framework } \\
\text { Component } \\
\end{array}$ & Description & $\begin{array}{c}\text { No. of Articles Containing } \\
\text { Component }\end{array}$ & $\begin{array}{l}\text { Component } \\
\text { Prevalence }\end{array}$ \\
\hline $\begin{array}{l}\text { Identify and } \\
\text { Enroll }\end{array}$ & $\begin{array}{l}\text { Described targeting and/or } \\
\text { enrollment process for a } \\
\text { medication synchronization } \\
\text { program }\end{array}$ & $14^{\mathrm{A}}$ & $53.8 \%$ \\
\hline $\begin{array}{l}\text { Medication } \\
\text { Review and } \\
\text { Patient } \\
\text { Assessment }\end{array}$ & $\begin{array}{c}\text { Described pre-alignment } \\
\text { medication review and patient } \\
\text { assessment }\end{array}$ & $6^{B}$ & $23.1 \%$ \\
\hline Align Refills & $\begin{array}{c}\text { Described a process of aligning } \\
\text { refills }\end{array}$ & $25^{c}$ & $96.2 \%$ \\
\hline $\begin{array}{l}\text { Preparation } \\
\text { of } \\
\text { Medications }\end{array}$ & $\begin{array}{l}\text { Described a process for } \\
\text { preparing patient's medications } \\
\text { for delivery }\end{array}$ & $23^{D}$ & $88.5 \%$ \\
\hline $\begin{array}{l}\text { Delivery of } \\
\text { Medications } \\
\text { and Other } \\
\text { Services }\end{array}$ & $\begin{array}{l}\text { Described the mechanism of } \\
\text { medication delivery as well as } \\
\text { any additional associated } \\
\text { services }\end{array}$ & $22^{\mathrm{E}}$ & $84.6 \%$ \\
\hline
\end{tabular}

Table 3 References
A. $8,10,11,27-37$
B. ${ }^{11,27-30,44,46}$
C. $8,10,11,15,16,27-46$
D. $8,10,11,15,16,27-37,39,41-46$
E. $8,10,11,15,16,28-39,41-43,45,46$ 
Table 4: Implementation Strategies Observed in The Literature ${ }^{24,25}$

\begin{tabular}{|c|c|c|c|}
\hline $\begin{array}{l}\text { Implementation } \\
\text { Strategies }\end{array}$ & $\begin{array}{l}\text { Total Mentions } \\
\text { of Strategy }\end{array}$ & $\begin{array}{l}\text { Prevalence of } \\
\text { Strategy }\end{array}$ & Strategy Examples \\
\hline Engage consumers ${ }^{A}$ & 26 & $100.0 \%$ & $\begin{array}{l}\text { Create recruitment script for } \\
\text { technicians to enroll patients. }\end{array}$ \\
\hline $\begin{array}{l}\text { Use evaluative and } \\
\text { interactive } \\
\text { strategies }^{\text {B }}\end{array}$ & 10 & $38.5 \%$ & $\begin{array}{l}\text { Medication synchronization } \\
\text { program trialed with small } \\
\text { patient group prior to scaling } \\
\text { up. }\end{array}$ \\
\hline $\begin{array}{l}\text { Adapt and tailor to } \\
\text { context }^{c}\end{array}$ & 12 & $46.1 \%$ & $\begin{array}{c}\text { Adapting the medication } \\
\text { delivery appointment to meet } \\
\text { the needs of patients, such as } \\
\text { home delivery }\end{array}$ \\
\hline $\begin{array}{c}\text { Develop } \\
\text { stakeholder } \\
\text { interrelationships }^{\mathrm{D}}\end{array}$ & 11 & $42.3 \%$ & $\begin{array}{c}\text { Identify and prepare } \\
\text { medication synchronization } \\
\text { champions }\end{array}$ \\
\hline $\begin{array}{l}\text { Train and educate } \\
\text { stakeholders }^{\mathrm{E}}\end{array}$ & 10 & $38.5 \%$ & $\begin{array}{c}\text { Have formal educational } \\
\text { documents prepared to train } \\
\text { pharmacy employees }\end{array}$ \\
\hline $\begin{array}{c}\text { Change } \\
\text { infrastructure }^{\mathrm{F}}\end{array}$ & 12 & $46.1 \%$ & $\begin{array}{c}\text { Adapt pharmacy management } \\
\text { software to track synchronized } \\
\text { patients. }\end{array}$ \\
\hline Support clinicians ${ }^{G}$ & 13 & $50 \%$ & $\begin{array}{l}\text { Create dedicated medication } \\
\text { synchronization technicians }\end{array}$ \\
\hline $\begin{array}{l}\text { Utilize financial } \\
\text { strategies }^{H}\end{array}$ & 3 & $11.5 \%$ & $\begin{array}{l}\text { Bundle other billable services } \\
\text { with synchronization } \\
\text { appointment }\end{array}$ \\
\hline $\begin{array}{l}\text { Provide interactive } \\
\text { assistance }\end{array}$ & 2 & $7.7 \%$ & $\begin{array}{l}\text { Centralizing medication } \\
\text { synchronization program } \\
\text { management to a single } \\
\text { location. }\end{array}$ \\
\hline
\end{tabular}

Table 4 References
A. $8,10,11,15,16,27-47$
B. ${ }^{11,16,34-36,38,41,46-48}$
C. $16,27,31,33,35,36,38,40,41,46-48$
D. $31,33-36,38-40,43,46,48$
E. $16,31,33-36,42,43,46,48$
F. 11,15,27,29-31,34-36,40,44,48
G. $10,11,15,27,29,31,34-36,38,43,44,48$
H. ${ }^{11,16,38}$
I. 33,40 